BMJ Open

Sport \&

Exercise

Medicine

\title{
Feasibility of a real-time self-monitoring device for sitting less and moving more: a randomised controlled trial
}

Anne Martin, ${ }^{1,2}$ Jacob M Adams, ${ }^{1}$ Christopher Bunn, ${ }^{3}$ Jason M R Gill, ${ }^{4}$ Cindy M Gray, ${ }^{3}$ Kate Hunt, ${ }^{5}$ Douglas J Maxwell, ${ }^{6}$ Hidde P van der Ploeg, ${ }^{7}$ Sally Wyke, ${ }^{3}$ Nanette Mutrie ${ }^{1}$ On behalf of the EuroFIT consortium

To cite: Martin A,

Adams JM, Bunn C, et al. Feasibility of a real-time selfmonitoring device for sitting less and moving more: a randomised controlled trial. BMJ Open Sport Exerc Med 2017;3:e000285.

doi:10.1136/bmjsem-2017000285

- Additional material is published online only. To view please visit the journal online (http://dx.doi.org/ 10.1136/bmjsem-2017000285)

Accepted 29 August 2017

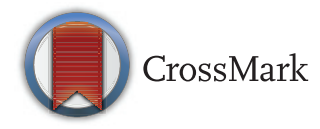

For numbered affiliations see end of article.

Correspondence to Professor Nanette Mutrie; nanette.mutrie@ed.ac.uk

\section{ABSTRACT}

Objectives Time spent inactive and sedentary are both associated with poor health. Self-monitoring of walking, using pedometers for real-time feedback, is effective at increasing physical activity. This study evaluated the feasibility of a new pocket-worn sedentary time and physical activity real-time selfmonitoring device (SitFIT).

Methods Forty sedentary men were equally randomised into two intervention groups. For 4 weeks, one group received a SitFIT providing feedback on steps and time spent sedentary (lying/sitting); the other group received a SitFIT providing feedback on steps and time spent upright (standing/stepping). Change in sedentary time, standing time, stepping time and step count was assessed using activPAL monitors at baseline, 4-week follow-up (T1) and 12-week (T2) follow-up. Semistructured interviews were conducted after 4 and 12 weeks.

Results The SitFIT was reported as acceptable and usable and seen as a motivating tool to reduce sedentary time by both groups. On average, participants reduced their sedentary time by 7.8 minutes/day $(95 \% \mathrm{Cl}-55.4$ to 39.7$)$ ( $\mathrm{T} 1)$ and by 8.2 minutes/day $(95 \% \mathrm{Cl}-60.1$ to 44.3$)$ (T2). They increased standing time by 23.2 minutes/day $(95 \% \mathrm{Cl}$ 4.0 to 42.5$)$ (T1) and 16.2 minutes/day $(95 \% \mathrm{Cl}-13.9$ to 46.2) (T2). Stepping time was increased by 8.5 minutes/day $(95 \% \mathrm{Cl} 0.9$ to 16.0$)$ (T1) and 9.0 minutes/day ( $95 \% \mathrm{Cl} 0.5$ to 17.5 ) (T2). There were no between-group differences at either follow-up time points.

Conclusion The SitFIT was perceived as a useful tool for self-monitoring of sedentary time. It has potential as a real-time self-monitoring device to reduce sedentary and increase upright time.

\section{INTRODUCTION}

Sedentary behaviour is a cluster of individual waking behaviours where sitting or lying is the dominant posture and energy expenditure is $\leq 1.5$ metabolic equivalents. ${ }^{1}$ Observational data indicate that a high level of total sedentary time is associated with increased risk of type 2 diabetes, cardiovascular disease (CVD) and all-cause and CVD

\section{What are the new findings?}

- The novel real-time self-monitoring device, the SitFIT, was perceived as a useful and practical tool for self-monitoring and changing sedentary time, upright time and step counts.

- The SitFIT, in combination with other behaviour change techniques, encouraged small improvements in the number of steps and time spent sedentary and standing even in a short intervention.

- The device can now be used in a fully powered trial.

mortality. $^{2-4}$ Although high volumes of physical activity may attenuate the effect of prolonged sitting, there is a clear association between sedentary time and risk of mortality. ${ }^{5}$ In addition, short-term intervention studies have shown that breaking up prolonged sedentary time with periods of light activity or standing provides favourable changes to the cardiometabolic risk profile. ${ }^{67}$ Evidence syntheses have reported that a statistically significant reduction in sedentary behaviour in adults is achievable. $^{8-10}$

Self-monitoring of physical activity, in particular when using a real-time feedback device such as a pedometer, has been shown to be an effective behaviour change technique in interventions aiming to increase physical activity levels. ${ }^{1-14} \mathrm{~A}$ device to allow self-monitoring of sitting time as well as physical activity could prove useful. $^{15}$

The present study was part of the European Fans in Training (EuroFIT) project. ${ }^{16}$ EuroFIT targets male fans of major football clubs and through a programme of weekly meetings encourages the reduction of sedentary behaviour and an increase in physical activity. ${ }^{16}$ The programme is 
modelled on the successful Football Fansin Training programme. ${ }^{17-19}$ A new device, the SitFIT (PAL Technology, Glasgow, Scotland, UK), was developed to provide real-time feedback through the integrated display of both sedentary and active time.

The aim of this study was to evaluate the feasibility of two prototypes of this new self-monitoring device (SitFIT). One prototype provided feedback on sedentary time and the other SitFIT device provided feedback on upright time. The study objectives were (1) to evaluate the acceptability of the SitFIT device, (2) to assess and compare changes in objectively measured sedentary time between the two prototypes and (3) to estimate change in sedentary time over 12 weeks to allow calculation of the effect sizes for a full-scale randomised controlled trial.

\section{METHODS}

\section{Study design, randomisation and participant recruitment}

This was a feasibility trial, and therefore the sample size was pragmatic and was not derived from a power calculation. Participants were randomly allocated, stratified by body mass index $\left(<27 \mathrm{~kg} / \mathrm{m}^{2}\right.$ vs $\left.\geq 27 \mathrm{~kg} / \mathrm{m}^{2}\right)$ calculated from measured weight and height, to one of two intervention conditions. One group received a SitFIT device that gave feedback on step count, sedentary time (minutes/day) and percentage sedentary time (SitFIT-SED), and another group received a SitFIT device that gave feedback on step count, upright time (minutes/day) and percentage sedentary time (SitFITUPR). Neither the participants nor the researchers conducting the data collection were blinded to group allocation. For details on randomisation, allocation and participant recruitment, see online supplementary file 1. The study was approved by the relevant Research Ethics Committee of the University of Edinburgh.

\section{Intervention}

The novel concepts underlying the SitFIT device were to use the front trouser pocket and to include a visual interface facilitating real-time self-monitoring of daily step accumulation and sedentary time (Gill JMR, Hawari N, Maxwell D, et al Development and validation of the SitFIT: a novel pocket-worn device to measure and provide feedback on sedentary behaviour and physical activity. Personal communication, 2017). To aid real-time interpretation of daily accumulation of sedentary and upright time throughout the day, the novel Sedentary Behaviour Index (SI) was developed.
The SI is the ratio of accumulated sedentary time to total wear time and is expressed as percentage of time spent sitting during the last hour as well as for the current day. This was also presented as a colour-coded bar with the percentage of sitting time in yellow and the percentage of upright time in green. Progressive tactile feedback was also provided by the SitFIT with one vibration after 15 minutes of sitting time, two vibrations after 30 minutes, three vibrations after 45 minutes and four vibrations after 60 minutes, giving feedback on periods of sitting uninterrupted. Participants had the choice to switch off the tactile feedback and change the vibration interval to 15 or 30 minutes.

Participants also received a study booklet (available on request from the corresponding author) providing: instructions on the functions and use of the SitFIT; instructions on how to set personalised daily goals for sedentary time and step counts; tips on how to reduce sitting time and increase stepping at home, at work and while travelling; and tables for recording daily sitting or upright time, SI and step counts. Evidence from pedometer-based interventions suggested that the beneficial effect of real-time self-monitoring is enhanced when combined with recording of daily values to reinforce behaviour change. ${ }^{11}$

Participants attended five research visits (figure 1). The intervention lasted 4 weeks. Participants were asked to calculate the average of the recorded days to generate baseline values for sedentary time and stepping. These formed the reference values from which the incremental behavioural goals for the intervention period were calculated. The three incremental behavioural goals were: (1) increasing daily steps by 1500 from the baseline value, (2) reducing sedentary time/increasing upright time (appropriate to their intervention allocation) by 30 minutes and (3) reducing percentage daily sedentary time by $5 \%$. A rationale for choosing the behavioural goals, and further details of the intervention, are provided in online supplementary file 1 .

\section{Data collection and outcome measures}

Separate semistructured interview guides were developed for each follow-up time point. The interview topics at T1 were: how the participants used the SitFIT and which aspects they found more and less useful (in particular, the feedback on sedentary or upright time). At $\mathrm{T} 2$, the interview focused on the maintenance of behaviour change. The first interview lasted 20-30 min, and the second interview lasted around 5 min.

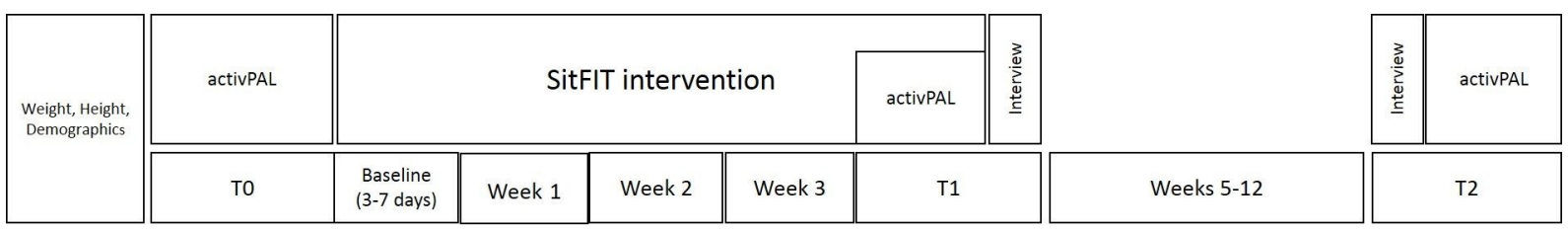

Figure 1 Intervention and data collection timeline. 
Quantitative outcomes were objectively measured time spent sedentary (sitting/lying), standing and stepping, and number of steps using the activPAL micro activity monitor (PAL Technologies, Glasgow, Scotland, $\mathrm{UK})$. The activPAL monitor is a triaxial accelerometer and inclinometer based device that is worn on the anterior upper thigh of the dominant leg and kept in place by an adhesive pad. The participants were asked to wear the activPAL monitor for seven consecutive days; they were instructed to only remove the device for bathing and swimming. Sleep and non-wear time were recorded by participants in log sheets. The activPAL monitor has been validated against direct observation ${ }^{20}$ and is sensitive to change in sitting time. ${ }^{21} 22$

\section{Data analysis}

Interviews were recorded digitally, transcribed and analysed thematically using an inductive coding approach in NVivo V.10. ${ }^{23}$ Three researchers (AM, CB and $\mathrm{CMG}$ ) independently coded three transcripts, noting emergent themes, before meeting to develop a coding framework. The validity of the coding framework was checked and agreed by independent coding of another two transcripts (AM and CB) before the full data set was coded. Once the coding was complete, themes were clustered into hierarchical structures, and the analysis was finalised through discussion (AM, CMG and $\mathrm{KH})$.

Descriptive summary statistics were generated for participant characteristics and objectively measured sedentary time and physical activity. ActivPAL data are presented as daily average of recorded days in minutes per day. Waking sitting and lying time were considered for the analysis, so daily average sleep time of recorded days was subtracted from sitting/lying data based on the self-report sleep log sheets. Between-group differences in daily average sitting, standing and stepping time and number of steps at 4 weeks (T1) and 12 weeks (T2) were determined using linear regression analysis corrected for baseline values. Missing followup data were replaced with the value of the previous time point, following an intention-to-treat approach. Cohen's $d$ effect sizes were calculated. The quantitative analyses were conducted in SPSS V.22. ${ }^{24}$ Data were reported as mean $\pm \mathrm{SD}$ and mean with $95 \%$ CIs as appropriate.

\section{RESULTS}

\section{Participant characteristics}

The participant flow diagram is shown in figure 2 and participant characteristics in table 1. Forty men were randomly allocated to one of the two intervention groups (SitFIT-SED and SitFIT-UPR). Two participants discontinued the intervention (one in each group) due to family/personal commitments. Baseline waking sedentary time (sitting/lying) was $10.1 \pm 1.6$ hours/day $(604.7 \pm 95.9 \mathrm{~min} /$ day $)$. Participants had a baseline step count of $11069 \pm 4036$ and a daily average stepping time of $2.2 \pm 0.8$ hours/day ( $131.4 \pm 48.0 \mathrm{~min} /$ day $)$.

\section{Participants' views on the practicality of using the SitFIT}

Most participants reported that the SitFIT device was easy to wear in a trouser pocket. However, some reflected on how the shape and size of pockets influenced the risk of losing the SitFIT. It was suggested that the SitFIT was more likely to fall out of the pocket when wearing trousers with wide (eg, gym shorts) or shallow pockets (eg, formal suit). Despite such concerns, of the 40 devices deployed, only two were lost. Some men expressed concerns that the accuracy of sedentary time feedback was compromised when they had shallow pockets or when the SitFIT changed position in the pocket.

Using the SitFIT for changing sitting and stepping behaviour Around half of the participants said they used the feedback displayed on the screen to track the progress towards their sedentary time and stepping goals for that week, whereas a similar number said they were interested in their daily sedentary time and step counts regardless of their goals. However, two said they did not use the SitFIT to monitor their progress at all (one because the novelty quickly wore off; the other because he felt he did not need numerical feedback).

Men who deliberately used the SitFIT to track progress towards their behavioural goals tended to obtain feedback around lunch time and/or after work and used the rest of the day to adapt their sitting and/or stepping behaviour.

Sometimes, for instance I'd check after work and see just how bad my day at work had been in terms of sitting down and then maybe walk home on that basis. (SitFIT-SED, 30-39 years)

Participants who tracked their progress of behaviour change regardless of the behavioural goals did so, for example, after they had made a conscious effort to break the sitting time or increase the step count. Some of these men also reflected that it was not so much the specific goal and numerical feedback that motivated them to look at their SitFIT; rather, it was developing an understanding of the day-to-day variation in their behaviours.

\section{Participants' views on the usability of the feedback for behaviour change}

Participants reported that receiving real-time feedback from the SitFIT on their stepping and sedentary time was informative and was experienced as motivating. Some participants said they felt more in control of changing their steps than their sitting or standing behaviour and reported social and environmental factors that negatively influenced their attempts to reduce time spent sedentary (online supplementary file 2). Men in the SitFIT-UPR group also realised the 
interdependency of increasing step count and upright time and so shifted their behaviour change efforts to increasing stepping.

I didn't think that much about how I am going to reduce my sitting time. I figured that if I increased my step count, 'cause I needed to do that anyway, then that will increase the amount of time I'm upright. (SitFIT-UPR, 30-39 years)

Participants in both intervention groups preferred the SI over feedback on minutes spent sedentary or upright. Men in the SitFIT-SED group perceived the large numbers of minutes accumulating over a day as intangible and off-putting. Another reported reason for the preference of the SI was that it was presented as a colour-coded bar which was perceived as helpful for visualising progress.

You can just look at the green and the orange without looking at anything else and say, 'whoops, too much orange there.' So you have to start walking. (SitFIT-UPR, 50-59 years)

The tactile feedback was considered useful to reduce sedentary behaviour by most men.

I loved the vibration thing, just to remind you. Even if it didn't make you stand up straight away it still put it in your head that you'd maybe been sitting down for longer than you wanted to be.

(SitFIT-UPR, 40-49 years)

According to the men, they were less likely to ignore the second buzz (eg, after $30 \mathrm{~min}$ sitting time, if set to buzz at 15 min intervals) but often found themselves in situations where they could not respond to the vibration (eg, at meetings).
Participants' feedback 8 weeks postintervention after returning the SitFIT

Overall, participants in both groups felt that even though they became more sedentary and walked less after returning the SitFIT, they remained less sedentary and more active than at the start of the intervention. Some men said they still used some of the behaviour change strategies they had learnt during the intervention but missed the numerical and tactile feedback from the SitFIT. Removal of the tactile feedback was directly attributed to them sitting longer.

I miss the reminder of the SitFIT, the half hourly buzz. Without that, I'm probably sitting for more, longer bouts although I'm trying to break it up throughout the day, I'm more prone to sitting for slightly longer. (SitFIT-SED, 30-39 years)

When you had that [the SitFIT] in your pocket you could look at it every sooften and you knew what your target was so you did it a bit more. But I would say previous to using the SitFIT I'm getting up about more at my work, than I was before. (SitFIT-UPR, 5059 years)

\section{Objectively measured changes in sedentary time and physical activities}

Table 2 summarises average daily time spent sedentary (sitting/lying), standing, stepping and step counts at $\mathrm{T} 0, \mathrm{~T} 1$ and $\mathrm{T} 2$ in each group and the combined study sample. Table 3 shows the betweengroup mean differences at $\mathrm{T} 1$ and $\mathrm{T} 2$ adjusted for baseline values. At T1, men in the SitFIT-SED group reduced their sedentary time by 15 minutes/day and increased their standing time by 12 minutes/day more than the SitFIT-UPR. At T2, the SitFIT-UPR

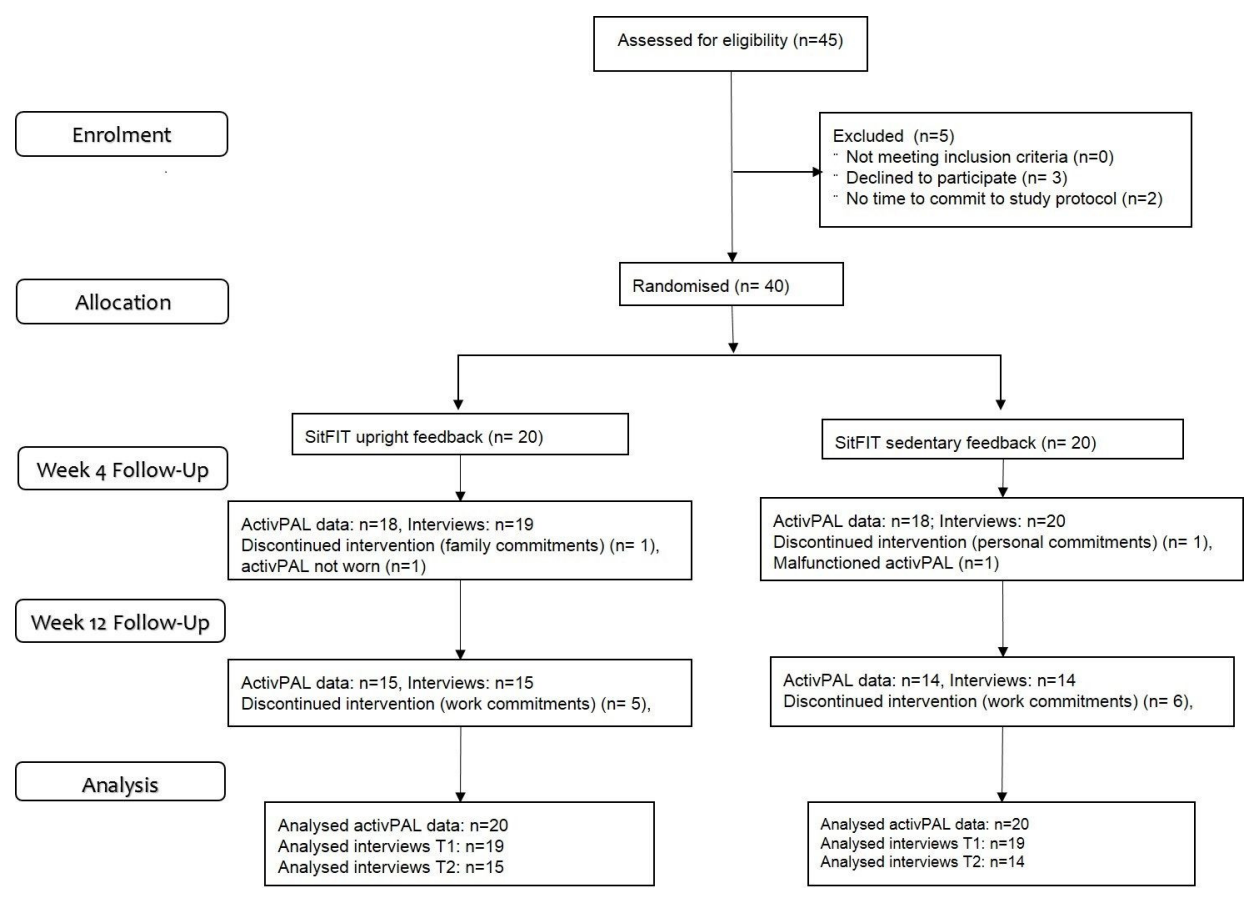

Figure 2 CONSORT flow diagram of recruitment and follow-up. CONSORT, Consolidated Standards of Reporting Trials. 
Table 1 Participant characteristics at baseline

\begin{tabular}{|c|c|c|c|c|c|c|}
\hline \multirow{3}{*}{ Age (years) } & \multicolumn{2}{|c|}{ Total } & \multicolumn{2}{|c|}{ SitFIT-UPR } & \multicolumn{2}{|c|}{ SitFIT-SED } \\
\hline & \multirow[t]{2}{*}{$\mathbf{N}$} & \multirow[t]{2}{*}{$\%$} & \multirow[t]{2}{*}{$\mathbf{N}$} & \multirow[t]{2}{*}{$\%$} & \multirow[t]{2}{*}{$\mathbf{N}$} & \multirow[t]{2}{*}{$\%$} \\
\hline & & & & & & \\
\hline 30-39 & 12 & 30 & 5 & 25.0 & 7 & 35.0 \\
\hline $40-49$ & 10 & 25 & 7 & 35.0 & 3 & 15.0 \\
\hline $50-59$ & 12 & 30 & 5 & 25.0 & 7 & 35.0 \\
\hline $60-65$ & 6 & 15 & 3 & 15.0 & 3 & 15.0 \\
\hline \multicolumn{7}{|l|}{ Highest education } \\
\hline Secondary school & 3 & 7.5 & 3 & 15.0 & 0 & 0 \\
\hline Technical qualification & 2 & 5.0 & 1 & 5.0 & 1 & 5.0 \\
\hline Undergraduate degree & 6 & 15 & 3 & 15.0 & 3 & 15.0 \\
\hline Master's degree or higher & 29 & 72.5 & 13 & 65.0 & 16 & 80.0 \\
\hline \multicolumn{7}{|l|}{ Employment } \\
\hline Employed & 38 & 95.0 & 20 & 100 & 18 & 90.0 \\
\hline Retired & 1 & 2.5 & 0 & 0 & 1 & 5.0 \\
\hline In education & 1 & 2.5 & 0 & 0 & 1 & 5.0 \\
\hline \multicolumn{7}{|l|}{ Income (£) } \\
\hline $10000-20000$ & 2 & 5.0 & 1 & 5.0 & 1 & 5.0 \\
\hline $20001-30000$ & 4 & 10.0 & 2 & 10.0 & 2 & 10.0 \\
\hline $30001-45000$ & 8 & 20.0 & 2 & 10.0 & 6 & 30.0 \\
\hline$\geq 45000$ & 26 & 65.0 & 15 & 75.0 & 11 & 55.0 \\
\hline \multicolumn{7}{|l|}{ Ethnic origin } \\
\hline White British & 34 & 85.0. & 18 & 90.0 & 16 & 80.0 \\
\hline White other & 6 & 15 & 2 & 10.0 & 4 & 20.0 \\
\hline \multicolumn{7}{|l|}{ Health status } \\
\hline Excellent & 10 & 25.0 & 4 & 20.0 & 6 & 30.0 \\
\hline Very good & 16 & 40.0 & 8 & 40.0 & 8 & 40.0 \\
\hline Good & 11 & 27.5 & 6 & 30.0 & 5 & 25.0 \\
\hline Fair & 3 & 7.5 & 2 & 10.0 & 1 & 5.0 \\
\hline Poor & 0 & 0 & 0 & 0 & 0 & 0 \\
\hline \multicolumn{7}{|l|}{$\mathrm{BMI} \geq 27 \mathrm{~kg} / \mathrm{m}^{2}$} \\
\hline Yes & 14 & 35.0 & 7 & 35.0 & 7 & 35.0 \\
\hline No & 26 & 65.0 & 13 & 65.0 & 13 & 65.0 \\
\hline
\end{tabular}

SED, sedentary time; UPR, upright time.

spent 64 fewer minutes sedentary and 28 more minutes standing per day compared with the SitFITSED group. Stepping time increased in the SitFITUPR group by five more minutes at $\mathrm{T} 1$ and 10 more minutes at T2, than in the SitFIT-SED group. Men in the SitFIT-SED group walked 434 steps more compared with SitFIT-UPR at T1. Whereas at T2, the SitFIT-URP group increased their step count by 1604 steps more than the SitFIT-UPR group.
Cohen's $d$ intervention effects were small for most outcomes at both follow-up times. Large SD and wide CIs suggested considerable intraindividual variability in all measures.

Statistical significance of the group differences was not assessed because this was a feasibility study and thus was not powered to detect intervention effects. 
Table 2 Time spent sedentary (sitting/lying), standing and stepping and step count at T0, T1 and T2. Within-group differences from baseline to T1 and T2

\begin{tabular}{|c|c|c|c|c|c|}
\hline \multirow[b]{2}{*}{ SitFIT-UPR } & \multirow{2}{*}{$\begin{array}{l}\text { Baseline } \\
\text { Mean (SD) }\end{array}$} & \multirow{2}{*}{$\begin{array}{l}\text { T1 (week 4) } \\
\text { Mean (SD) }\end{array}$} & \multirow{2}{*}{$\begin{array}{l}\text { T2 (week 12) } \\
\text { Mean (SD) }\end{array}$} & \multicolumn{2}{|c|}{ Within-group differences } \\
\hline & & & & $\Delta \mathrm{T} 1(95 \% \mathrm{Cl})$ & $\Delta$ T2 $(95 \% \mathrm{Cl})$ \\
\hline \multicolumn{6}{|l|}{ Sitting/lying* } \\
\hline $\min /$ day & $618.5(99.6)$ & $613.9(157.4)$ & $562.2(135.3)$ & $-4.6(-75.4,66.3)$ & $-56.3(-86.8,26.7)$ \\
\hline$\%$ wear time & $64.1(9.8)$ & $63.6 .0(17.5)$ & $58.7(15.1)$ & & \\
\hline \multicolumn{6}{|l|}{ Standing* } \\
\hline $\min /$ day & $238.1(63.1)$ & $254.5(64.6)$ & $265.0(83.9)$ & $16.4(-8.5,41.2)$ & $26.9(-23.7,77.5)$ \\
\hline$\%$ wear time & $24.8(7.0)$ & $26.4(6.9)$ & $27.6(8.9)$ & & \\
\hline \multicolumn{6}{|l|}{ Stepping $\dagger$} \\
\hline $\min /$ day & $135.1(55.1)$ & $145.5(55.9)$ & $148.6(53.7)$ & $10.4(-0.1,20.9)$ & $13.5(1.3,25.6)$ \\
\hline$\%$ wear time & $14.0(6.0)$ & $15.1(5.9)$ & $15.6(5.9)$ & & \\
\hline \multicolumn{6}{|l|}{ Step count $\dagger$} \\
\hline Steps/day & 10509 (3499) & $10655(3593)$ & $13090(5958)$ & $147(-1197,1490)$ & $2582(-354,5517)$ \\
\hline \multicolumn{6}{|l|}{ SitFIT-SED } \\
\hline \multicolumn{6}{|l|}{ Sitting/lying* } \\
\hline $\min /$ day & $591.0(92.5)$ & $579.9(165.4)$ & $631.0(153.2)$ & $-11.1(-81.3,59.1)$ & $40.0(-38.6,118.5)$ \\
\hline$\%$ wear time & $62.1(8.4)$ & $60.7(17.2)$ & $66.5(15.3)$ & & \\
\hline \multicolumn{6}{|l|}{ Standing* } \\
\hline $\min /$ day & $232.2(49.9)$ & $262.3(68.6)$ & $237.6(56.5)$ & $30.1(-1.4,61.6)$ & $5.4(-31.3,42.2)$ \\
\hline$\%$ wear time & $24.5(5.4)$ & $27.6(7.3)$ & $25.1(5.8)$ & & \\
\hline \multicolumn{6}{|l|}{ Stepping* } \\
\hline $\min /$ day & $127.9(41.2)$ & $134.55(41.2)$ & $132.7(46.0)$ & $6.6(-5.1,18.3)$ & $4.8(-8.0,17.6)$ \\
\hline$\%$ wear time & $13.6(4.8)$ & $14.1(4.4)$ & $14.0(5.0)$ & & \\
\hline \multicolumn{6}{|l|}{ Number of steps } \\
\hline Steps/day & $11602(4540)$ & 11969 (4413) & $11552(4486)$ & $367(-663,1396)$ & $-50(-3249,3151)$ \\
\hline \multicolumn{6}{|l|}{ Total } \\
\hline \multicolumn{6}{|l|}{ Sitting/lying $\ddagger$} \\
\hline $\min /$ day & 604.7 (95.9) & $596.9(160.3)$ & $596.6(146.8)$ & $-7.8(-55.4,39.7)$ & $-8.2(-60.6,44.3)$ \\
\hline$\%$ wear time & $63.1(9.0)$ & $62.1(16.3)$ & $62.6(15.5)$ & & \\
\hline \multicolumn{6}{|l|}{ Standing $\ddagger$} \\
\hline $\min /$ day & 235.1 (56.2) & $258.4(65.9)$ & $251.3(72.0)$ & $23.2(4.0,42.5)$ & $16.2(-13.9,46.2)$ \\
\hline$\%$ wear time & $24.6(6.2)$ & $27.0(7.1)$ & $26.3(7.5)$ & & \\
\hline \multicolumn{6}{|l|}{ Stepping $\S$} \\
\hline $\min /$ day & $131.4(48.0)$ & $140.0(48.7)$ & $140.4(49.9)$ & $8.5(9.9,16.0)$ & $9.0(0.5,17.5)$ \\
\hline$\%$ wear time & $13.8(5.3)$ & $14.6(5.1)$ & $14.8(5.5)$ & & \\
\hline \multicolumn{6}{|l|}{ Number of steps $\S$} \\
\hline Steps/day & $11069(4040)$ & 11329 (4036) & 12301 (5243) & $260(-542,1061)$ & $1232(-886,3351)$ \\
\hline
\end{tabular}

Percentage of wear time (ie, non-sleep wear time) exceeds $100 \%$ by up to $5 \%$ at places. This might be due to underestimation of sleep and non-wear time (recall bias).

*Sample size $n=20$.

$\dagger$ Sample size $n=19$.

$\ddagger$ Sample size $n=40$.

$\S$ Sample size $n=39$.

SED, sedentary time; UPR, upright time. 


\section{DISCUSSION}

\section{Summary of the findings}

The objectives of this study were to gain insight into men's experiences of using the SitFIT, to assess and compare objectively measured changes in sedentary time and stepping between two different real-time feedback types and to estimate effect sizes for future power calculation.

Participants reported that the numerical feedback on step counts and percentage time spent sedentary was the most important factor in supporting them to change their behaviour. Although about half of the men reported that they did not change their behaviour during the intervention and at 2 months postintervention, the men reflected that having had a target goal to work towards during the intervention was helpful for behaviour change. Participants felt more in control of making changes to their walking routine than to their sedentary time, which was often perceived to be constrained by the physical work environment and social norms. Many participants reported trying to achieve their sedentary time goals by increasing their step count. The vibration function of the SitFIT was recognised as a useful reminder of how long the participants had been sitting uninterrupted, even though they were not always able to act on it immediately. Concerns over inaccuracy of the SitFIT did not appear to affect engagement with the device, perhaps because inaccuracies were minimal. ${ }^{25}$

It appeared not to make a difference to objectively measured sedentary and standing time whether participants received feedback on sedentary time or on upright time, either immediately after the 4-week intervention or 8 weeks later.

\section{Comparison with other studies}

A recent study assessed the effect of organisational support strategies alone or in combination with an activity tracker to reduce sitting in office workers. ${ }^{25}$ The activity tracker provided feedback on sitting, standing, stepping, sitting breaks, posture and sleep via a smartphone application, along with vibration feedback from the device positioned at the lower back. The use of the posture monitoring device did not result in beneficial changes in time spent standing between baseline and immediate postintervention follow-up, ${ }^{25}$ whereas in the present study, participants increased their standing time. One reason for the difference in the findings might be the low compliance of using the activity tracker as self-monitoring tool and the need for a smartphone. Furthermore, unlike SitFIT, the activity tracker had no function to remind the participants about the length of sitting bouts and this kind of prompt can successfully increase standing time ${ }^{26}$ and number of breaks in periods of sitting. ${ }^{27}$

\section{Strengths and limitations}

The strengths of this study were the novelty of the selfmonitoring device under investigation and the mixedmethods approach using a randomised two-arm trial to test the feasibility of two prototypes of the SitFIT.

Nevertheless, the following limitations need to be considered. This study was a short-term feasibility study with an intervention duration of 4 weeks, which might not be long enough for sustained behaviour change. $^{28} 29$ Recruitment, intervention and follow-up took place between March and October, so seasonality might have influenced the observed behaviour changes and participant feedback. The responses to the acceptability of the SitFIT and the subsequent behaviour change might be different in less active men or those from a more socioeconomically deprived and less educated backgrounds.

\section{Implications of the findings}

Participants' feedback about the SitFIT, as reported here, informed the final design of the SitFIT for evaluation in a full-scale randomised controlled trial in the EuroFIT project. The design chosen was to display upright time, retain step count, sedentary index and the vibrating reminder. Of importance in informing the final design were: dependency between time spent upright and step count expressed by the SitFIT-UPR

Table 3 Baseline-adjusted mean between-group differences and Cohen's $d$ effect sizes in sedentary, standing and stepping time and number of steps

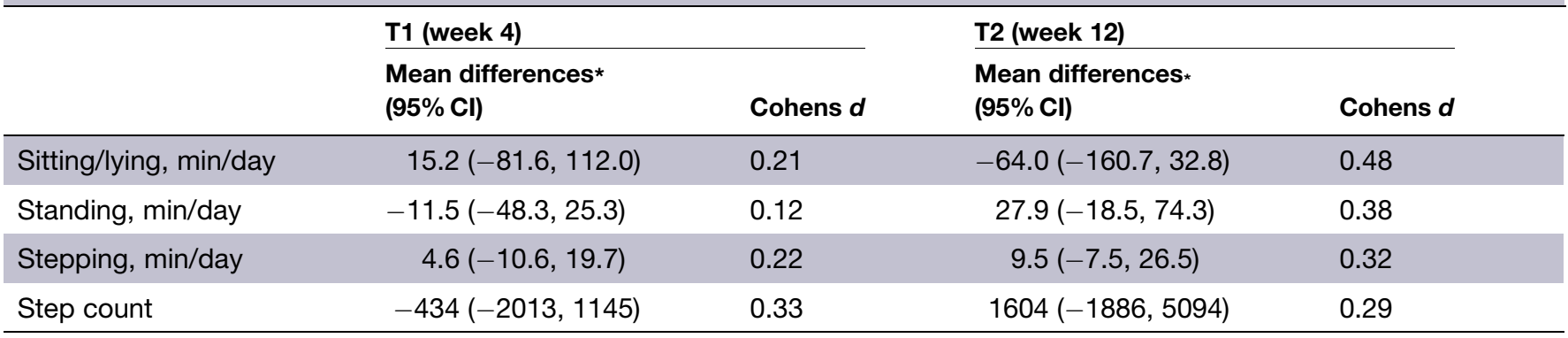

*Mean differences compared with the SitFIT-UPR group.

UPR, upright time. 
group; the ability to positively affect upright time over the course of day (whereas sedentary time cannot be 'reduced' throughout the day, only maintained or increased) ; trends from the quantitative data in favour of the upright time version of display; and participants' positive views about the sedentary index, step count and vibration function.

\section{CONCLUSION}

The novel real-time self-monitoring device, the SitFIT, was perceived as a useful and practical tool for changing sedentary time, upright time and step counts. The SitFIT, in combination with other behaviour change techniques, encouraged small improvements in the number of steps and time spent sedentary and standing in a short intervention. Our fully powered trial will further investigate this. The SitFIT seems a promising tool for integration in more intensive intervention programmes.

\author{
Author affiliations \\ ${ }^{1}$ Physical Activity for Health Research Centre, Institute for Sport Physical \\ Education and Health Sciences, University of Edinburgh, Edinburgh, UK \\ ${ }^{2}$ Department of Computer and Information Sciences, Digital Health and \\ Wellness Group, University of Strathclyde, Glasgow, UK \\ ${ }^{3}$ Institute of Health and Wellbeing, College of Social Sciences, University of \\ Glasgow, Glasgow, UK \\ ${ }^{4}$ Institute of Cardiovascular and Medical Sciences, College of Medical, \\ Veterinary and Life Sciences, University of Glasgow, Glasgow, UK \\ ${ }^{5} \mathrm{MRC} / \mathrm{CSO}$ Social and Public Health Sciences Unit, Institute of Health and \\ Wellbeing, University of Glasgow, Glasgow, UK \\ ${ }^{6}$ PAL Technologies Ltd, Glasgow, UK \\ ${ }^{7}$ Department of Public and Occupational Health, Amsterdam Public Health \\ Research Institute, VU University Medical Center, Amsterdam, The \\ Netherlands
}

Acknowledgements We would like to thank Yao Lu for her contribution in collecting data for this study.

Contributors AM conducted the study, analysed the data and drafted the manuscript. $\mathrm{CB}, \mathrm{KH}$ and $\mathrm{CMG}$ conceptualised the study and contributed to the qualitative data analysis and manuscript writing. JMA assisted in the data collection and manuscript revisions. JMRG, HPvdP, DJM, SW and NM conceptualised the study and contributed to writing the manuscript. NM is the guarantor.

Funding This study has received funding from the European Union's Seventh Framework Programme for research, technological development and demonstration under grant agreement no. 602170. The materials presented and views expressed here are the responsibility of the authors only. The EU Commission takes no responsibility for any use made of the information set out. KH is supported by the UK Medical Research Council and Chief Scientist Office (MC_UU_12017/12; SPHSU12).

Competing interests The SitFIT device was developed by PAL Technologies, which is a member of the EuroFIT consortium. DJM is CEO of PAL

Technologies. All other authors declare no competing interest.

Ethics approval Moray House School of Education Ethics Committee, University of Edinburgh

Provenance and peer review Not commissioned; externally peer reviewed.

Open Access This is an Open Access article distributed in accordance with the Creative Commons Attribution Non Commercial (CC BY-NC 4.0) license, which permits others to distribute, remix, adapt, build upon this work noncommercially, and license their derivative works on different terms, provided the original work is properly cited and the use is non-commercial. See: http:// creativecommons.org/licenses/by-nc/4.0/
(C) Article author(s) (or their employer(s) unless otherwise stated in the text of the article) 2017. All rights reserved. No commercial use is permitted unless otherwise expressly granted.

\section{REFERENCES}

1. SBRN. Standardized use of the terms "sedentary" and "sedentary behaviours". Appl Physiol Nutr Metab 2012;37:540.

2. Biswas A, Oh PI, Faulkner GE, et al. Sedentary time and its association with risk for disease incidence, mortality, and hospitalization in adults: a systematic review and meta-analysis. Ann Intern Med 2015;162:123-32.

3. Chau JY, Grunseit AC, Chey T, et al. Daily sitting time and all-cause mortality: a meta-analysis. PLoS One 2013;8:e80000.

4. Proper KI, Singh AS, van Mechelen W, et al. Sedentary behaviors and health outcomes among adults: a systematic review of prospective studies. Am J Prev Med 2011;40:174-82.

5. Ekelund U, Steene-Johannessen J, Brown WJ, et al. Does physical activity attenuate, or even eliminate, the detrimental association of sitting time with mortality? A harmonised meta-analysis of data from more than 1 million men and women. The Lancet 2016;388:1302-10.

6. Chastin SF, Egerton T, Leask C, et al. Meta-analysis of the relationship between breaks in sedentary behavior and cardiometabolic health. Obesity 2015;23:1800-10.

7. Henson J, Davies MJ, Bodicoat DH, et al. Breaking up prolonged sitting with standing or walking attenuates the postprandial metabolic response in postmenopausal women: a randomized acute study. Diabetes Care 2016;39:130-8.

8. Martin A, Fitzsimons C, Jepson R, et al. Interventions with potential to reduce sedentary time in adults: systematic review and metaanalysis. Br J Sports Med 2015;49:1056-63.

9. Prince SA, Saunders TJ, Gresty K, et al. A comparison of the effectiveness of physical activity and sedentary behaviour interventions in reducing sedentary time in adults: a systematic review and meta-analysis of controlled trials. Obes Rev 2014;15:905-19.

10. Shrestha N, Kukkonen-Harjula KT, Verbeek JH, et al. Workplace interventions for reducing sitting at work. Cochrane Database Syst Rev 2016;3:CD010912.

11. Bravata DM, Smith-Spangler C, Sundaram V, et al. Using pedometers to increase physical activity and improve health: a systematic review. JAMA 2007;298:2296-304.

12. Heath GW, Parra DC, Sarmiento OL, et al. Evidence-based intervention in physical activity: lessons from around the world. Lancet 2012;380:272-81.

13. Michie S, Abraham $\mathrm{C}$, Whittington $\mathrm{C}$, et al. Effective techniques in healthy eating and physical activity interventions: a meta-regression. Health Psychol 2009;28:690-701.

14. Richardson CR, Newton TL, Abraham JJ, et al. A meta-analysis of pedometer-based walking interventions and weight loss. Ann Fam Med 2008;6:69-77.

15. Sanders JP, Loveday A, Pearson N, et al. Devices for self-monitoring sedentary time or physical activity: a scoping review. J Med Internet Res 2016;18:e90.

16. van Nassau F, van der Ploeg HP, Abrahamsen F, et al. Study protocol of European Fans in Training (EuroFIT): a four-country randomised controlled trial of a lifestyle program for men delivered in elite football clubs. BMC Public Health 2016;16:598.

17. Gray CM, Hunt K, Mutrie N, et al. Football Fans in Training: the development and optimization of an intervention delivered through professional sports clubs to help men lose weight, become more active and adopt healthier eating habits. BMC Public Health 2013;13:232

18. Hunt K, Wyke S, Gray CM, et al. A gender-sensitised weight loss and healthy living programme for overweight and obese men delivered by Scottish Premier League football clubs (FFIT): a pragmatic randomised controlled trial. Lancet 2014;383:1211-21.

19. Wyke S, Hunt K, Gray CM, et al. Football Fans in Training (FFIT): a randomised controlled trial of a gender-sensitised weight loss and healthy living programme for men - end of study report. Public Health Res 2015;3:1-130.

20. Grant PM, Ryan CG, Tigbe WW, et al. The validation of a novel activity monitor in the measurement of posture and motion during everyday activities. Br J Sports Med 2006;40:992-7.

21. Kang M, Rowe DA. Issues and challenges in sedentary behavior measurement. Meas Phys Educ Exerc Sci 2015;19:105-15.

22. van Nassau F, Chau JY, Lakerveld J, et al. Validity and responsiveness of four measures of occupational sitting and standing. Int J Behav Nutr Phys Act 2015;12:144

23. Castleberry A. NVivo 10 [software program]. Version 10. QSR International; 2012. Am J Pharm Educ 2014;78:25. 
24. SPSS. IBM SPSS statistics 22. Algorithms. Chicago: IBM SPSS Inc. 2013.

25. Brakenridge CL, Fjeldsoe BS, Young DC, et al. Evaluating the effectiveness of organisational-level strategies with or without an activity tracker to reduce office workers' sitting time: a clusterrandomised trial. Int J Behav Nutr Phys Act 2016;13:115.

26. Aadahl M, Linneberg A, Møller TC, et al. Motivational counseling to reduce sitting time: a community-based randomized controlled trial in adults. Am J Prev Med 2014;47:576-86.
27. Evans RE, Fawole HO, Sheriff SA, et al. Point-of-choice prompts to reduce sitting time at work: a randomized trial. Am J Prev Med 2012;43:293-7.

28. Lally P, Gardner B. Promoting habit formation. Health Psychol Rev 2013;7(suppl 1):S137-58.

29. Lally P, van Jaarsveld CHM, Potts HWW, et al. How are habits formed: modelling habit formation in the real world. Eur $J$ Soc Psychol 2010;40:998-1009. 